\title{
Industry Oriented Smart and Automated Process Control System
}

\author{
Pratik Kulkarni ${ }^{1}$, Siddharth Munot ${ }^{1}$, Nischay Meshram ${ }^{1}$ \\ 1. B. E. student Electronics and Telecommunication Department P.V.P.I.T. Pune
}

\begin{abstract}
Dealing with waste water is a global crisis. The chemical industry, along with touching new horizons of discoveries is equally dominating the field of water pollution. The waste from these industries may prove fatal, thus treatment of water from the chemical industry should be at the apex of our priorities. Various processes like gravity settling, filtration, air stripping, or adsorption to activated carbon are the processes that leave a waste stream to be treated and disposed, among these advanced oxidation process $(A O P)$ is the most trusted method. Advanced oxidation process (AOP) utilizes the strong oxidizing power of hydroxyl radicals that can reduce organic compounds to harmless end products such as carbon dioxide and water. This Can be achieved through controlling $\mathrm{pH}$.
\end{abstract}

Key words: $A O P, p H$, Industrial waste water.

\section{Introduction:}

In current scenario water purification process is carried out manually.

\section{Challenge 1}

Efficient labour and extreme accuracy is required while dealing with current purification process.

\section{Challenge 2}

Lot of funds are invested for training workers even though the results are not assured.

\section{Challenge 3}

The automation options present today are based on SCADA which is equally costly.

Hence the demand for a cheaper and efficient alternative for the current system is increasing alarmingly. Thus considering the importance and impact on environment we propose an alternative to such costly systems. This concept will help to reduce the human interference in water treatment process and assure the quality of treatment. Along with this various readings and behaviour of the plant in various circumstances can also be observed. This can help in further studies and research. The project mainly concentrates on maintaining the $\mathrm{pH}$ required for the AOP and monitoring the chemical content in various tanks. The controlling is done through motors and communication with the computer is done through the serial communication. An ATMEGA series micro-controller was preferred, as it consists a ten bit ADC (Analog to Digital Converter) a significant level of precision in sensing can be obtained. Also by using the RF (CC2500) module a wireless communication can be established.

\section{Project Discription:}

Project demanded controlling of tank levels considering the $\mathrm{pH}$ of the solution at various states. Thus tank level and $\mathrm{pH}$

Sensors were the two most important devices in the project. A controller with high efficiency, accuracy and sufficient resolution was required.

Accordingly ATMEGA 32 was selected as it has 8 channel 10 bit ADC. The basic need o the project was $\mathrm{pH}$ sensing. The working and controlling o the valves is totally dependent on the $\mathrm{pH}$ sensed in the tanks. Thus it was most important to select an appropriate sensor for $\mathrm{pH}$ measurement. Thus CL51B of polymon instrument was selected. The specifications of the sensor are given below

Specifications:-

Model No. - $\quad$ LP-130-01

Electrode Specifications:

Electrode Type - KCL filled electrode

Liquid Junction Porous pin

PH Range $-0-14 \mathrm{pH}$

Operating Temperature $-0-70{ }^{\circ} \mathrm{C}$

Cable Length $\quad-70 \mathrm{~cm}$

Termination Type - BNC connector

Cable Type - Coaxial, 2 wire Teflon low noise shielded cable 
Graphical presentation: The system is automated but also monitoring can be done through graphical interface (computer). A separate java application was developed for providing a graphical view and monitoring of the plant. At times controlling can also be done through this the computer. The use of java made it usable in any operating system of any core. The interface is also user friendly which would not require a skilled labour to handle it. The snapshots of the application along with its functions can be seen in these figures.

\section{A. LOGIN PAGE:}

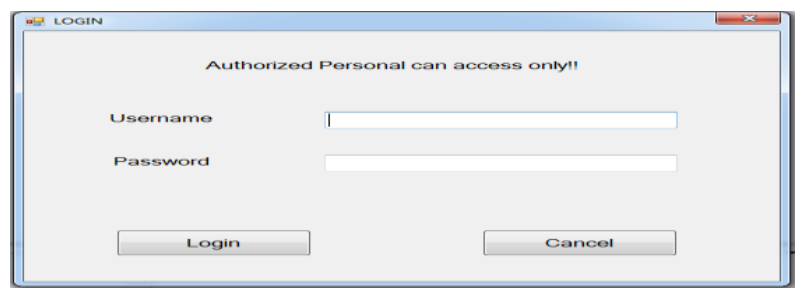

Fig.1

This is the login screen where operator will have to insert valid username and password in the respective fields to get access to the module. Once the operator is logged in he will be provided with various modes.

\section{B. TESTING MODE:} motors.

Here the operator can select the testing mode where he can test the proper functioning of sensors and
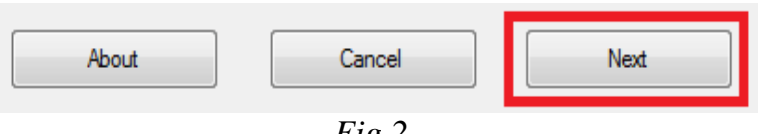

Fig.2

After selecting the testing mode operator has to click on next to go to the next window and cancel to close the window.

COM Port Selection

Select a ComPort

Fig.3

At the same time before clicking next the specific com port has to be selected to which the cable is connected.

C. SENSOR TEST:

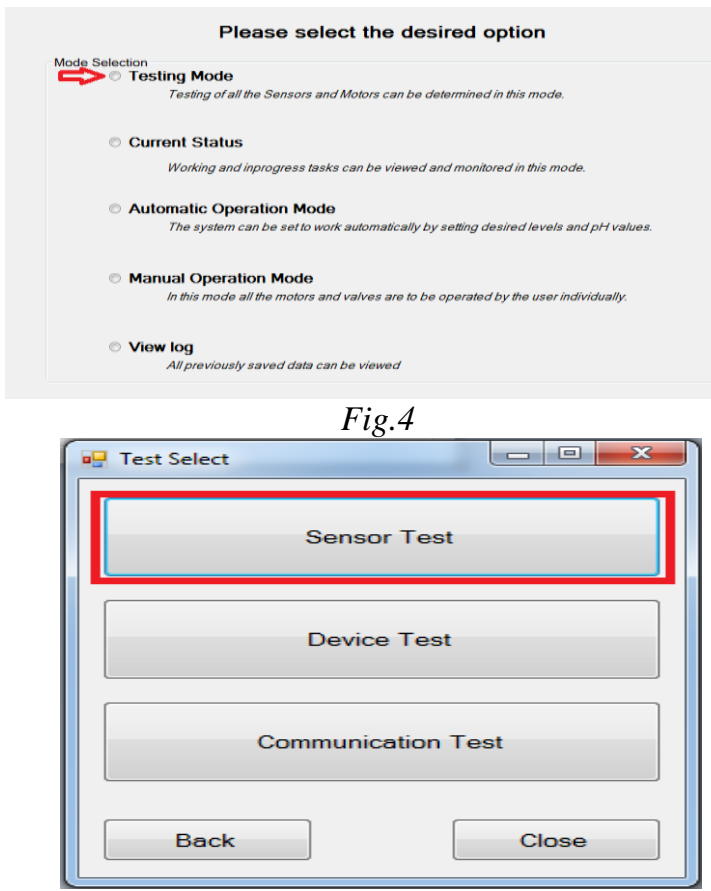

Fig.5

When the operator finds error in the functionality of any sensor from its recorded values he can click on the sensor test button. 


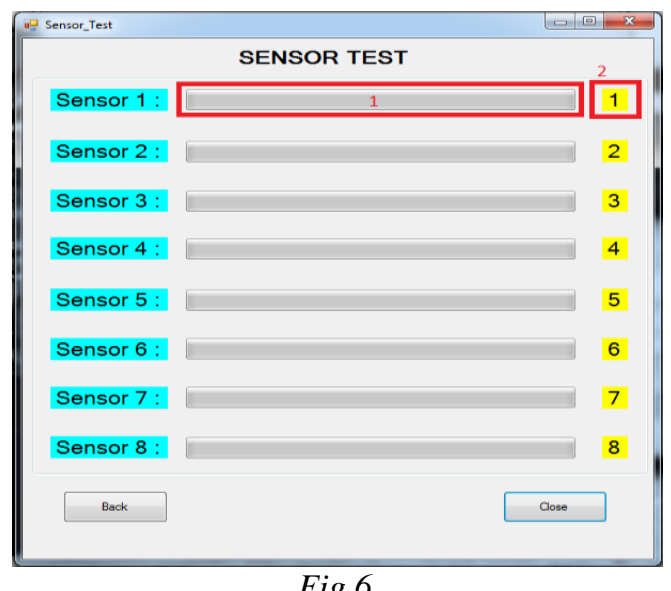

The sensor test window gives the value in 2 ways:

1. With the help of a progress bar where the varying values will be observed.

2. In the numeric form just to the right of progress bar.

After sensor test is the button of device test it will show the whether device connected are working properly or not.

Initially all the devices will be in the OFF state and each device can be checked individually by the operator. The devices when in the OFF state will be denoted by the red colour in the background for each switch. All the devices can be turned ON and OFF by the all ON and all OFF buttons.

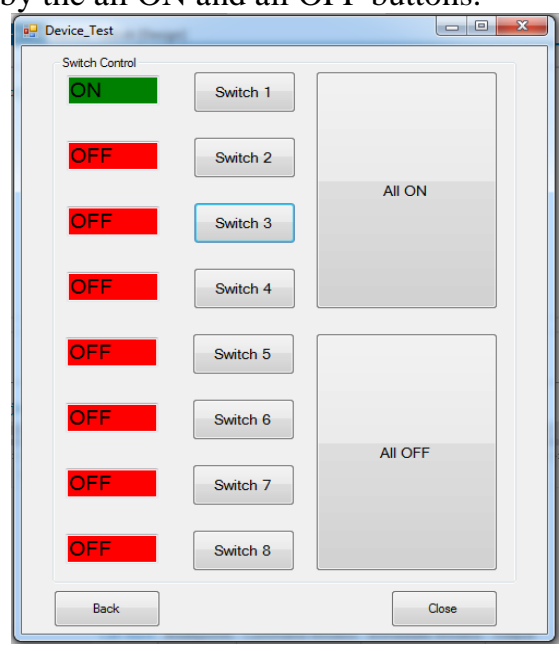

Fig.7

Similarly the ON state is denoted by green colour as shown above.

\section{CURRENT STATUS:}

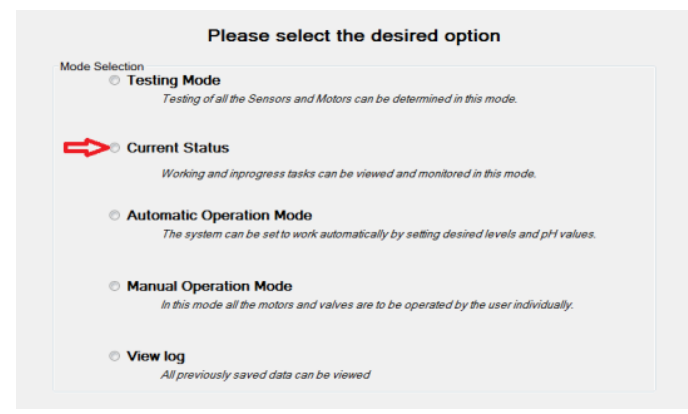

Fig.8

The next mode is the current status mode where the operator can view and monitor the working and in progress tasks. 


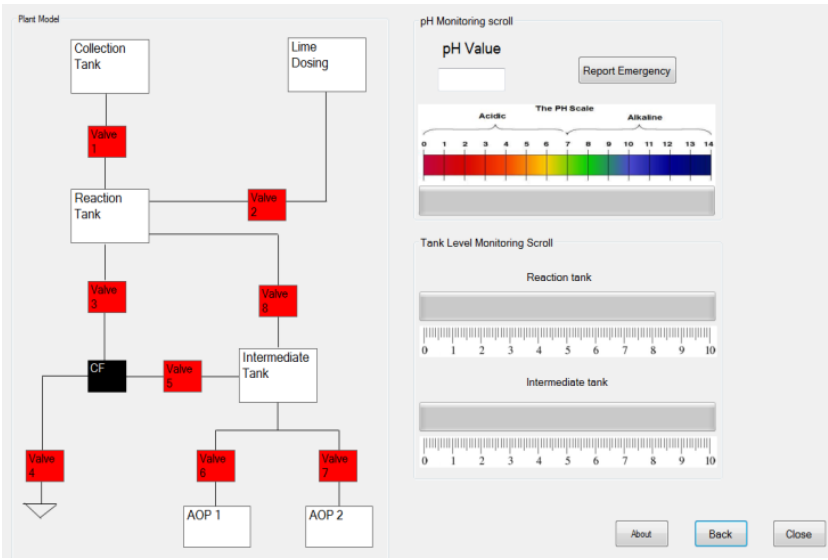

Fig.8

Once the current status is selected by the operator the complete diagram of the plant can be seen by the operator with the current $\mathrm{pH}$ value with the reaction and intermediate tank levels as shown below.

\section{E. AUTOMATIC MODE:}

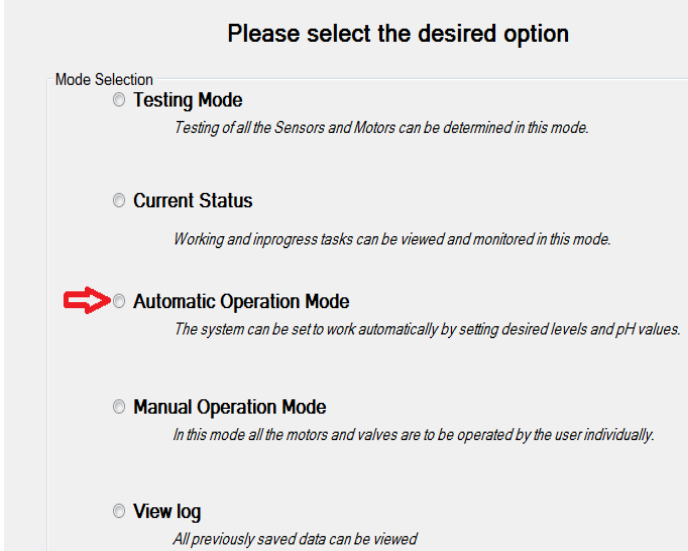

Fig. 9

In the automatic mode the operator can set the $\mathrm{pH}$ value and the process will be carried out for that specific $\mathrm{pH}$ value. The value can be entered in the textbox as shown below and it can be stored by clicking "Set the Value" button.

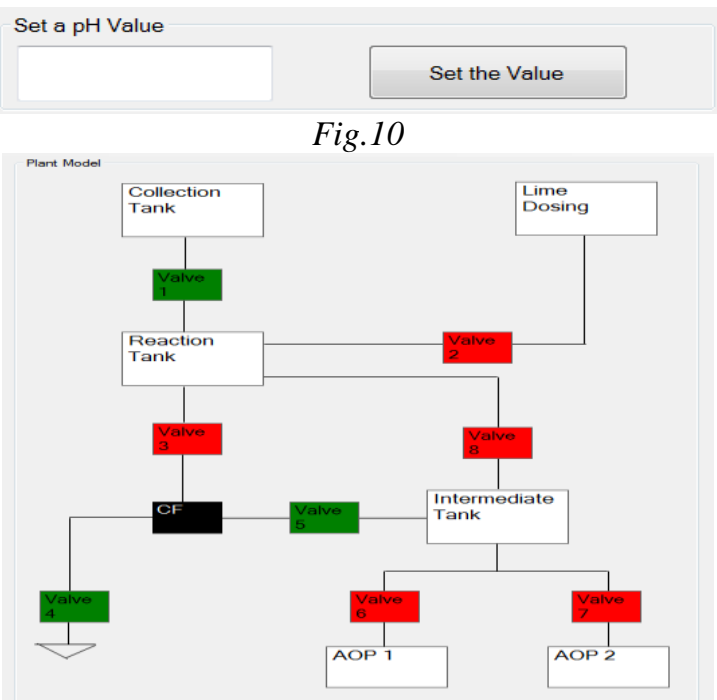

Fig.11

For the automatic mode the plant model will look as shown in the figure. 


\section{F. MANUAL MODE:}

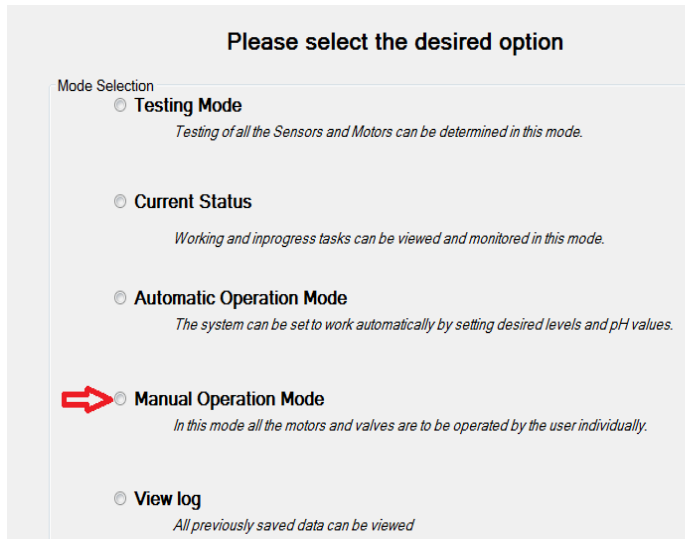

Fig.12

This is another mode provided for the operator which will help him set the pH values as per the current requirements manually.

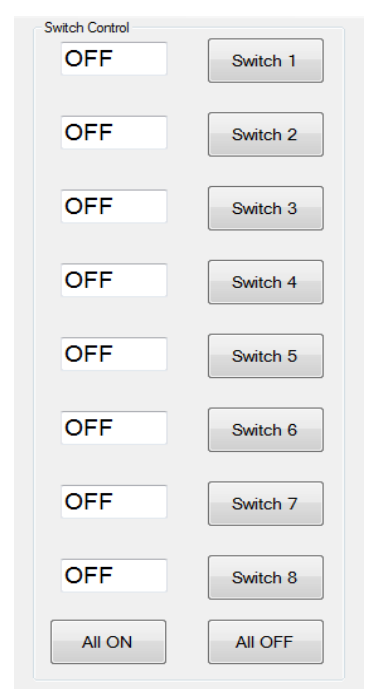

Fig. 13

In the manual mode operator will have to set the switching of the valves all by himself by operating the swithes as shown in the figure.

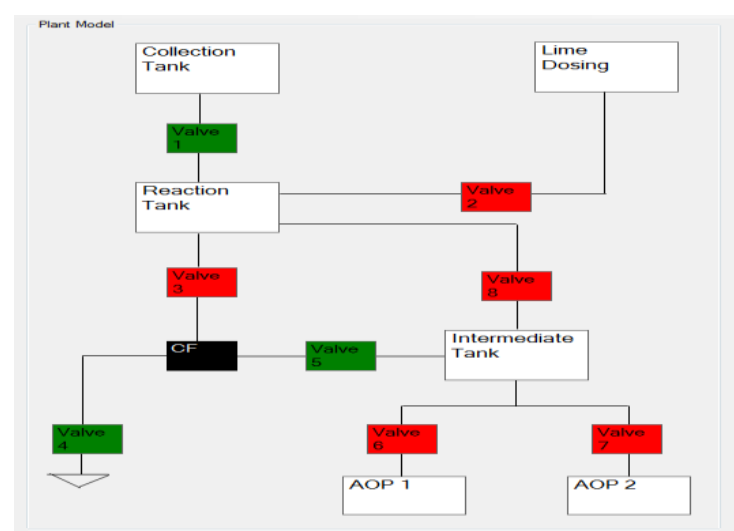

Fig. 14

As per the switches selected by the operator corresponding valves will be ON or OFF in the manual mode as shown. 


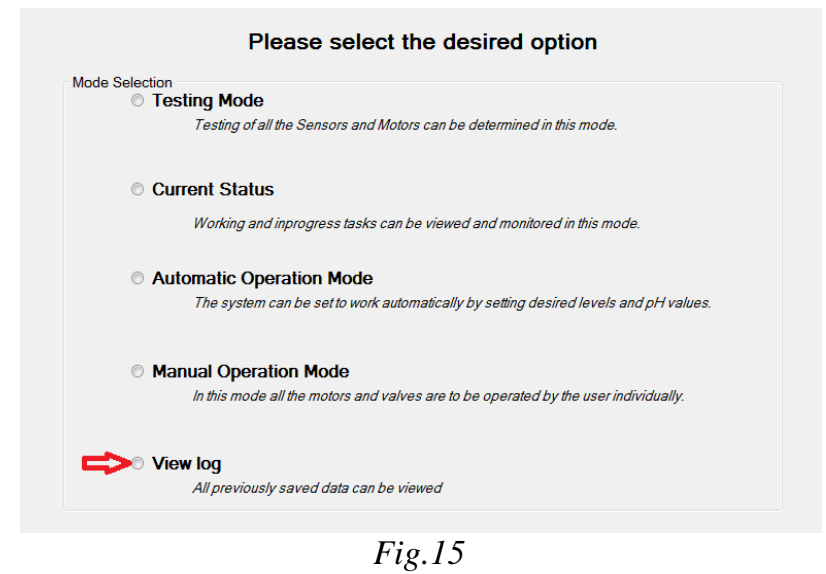

The operator will also be provided with the view log option where he will be able to view the previously stored data.

The log can be viewed in 2 ways:

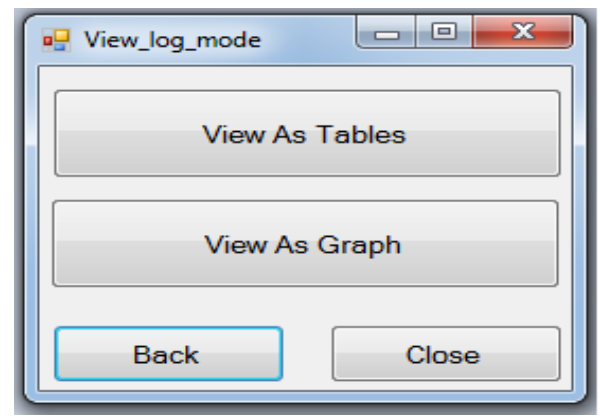

Fig.16

1. In the form of tables (Excel sheet).

2. In the form of graph.

\section{Operation:}

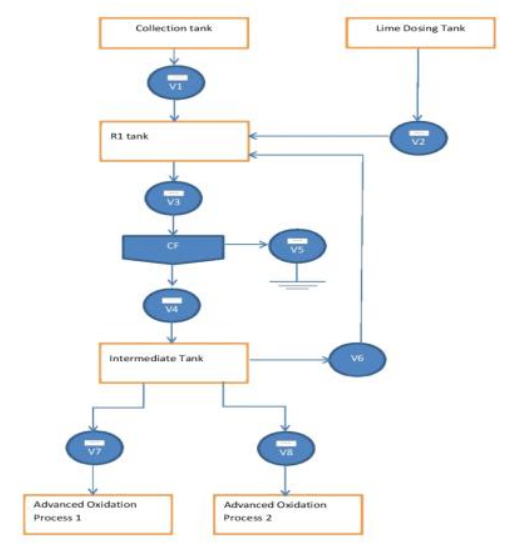

Fig. 17

The waste water treatment plant is divided into various sections. The preliminary treatment involves monitoring the $\mathrm{pH}$ of the waste. This is a very tedious task as the $\mathrm{pH}$ has to be controlled considering the level of chemicals in various tanks.

The wastes from various processes in the plant are accumulated in the collection tank.

But the water available in collection tank is highly acidic having $\mathrm{pH}$ in the range of 1.2 to 2 which cannot be carried out with aerobic process. This waste is then passed on to the reaction tank through a valve1 where the $\mathrm{pH}$ has to be maintained at 9 . This is done by lime dosing by opening valve v2.For proper working; the tank level of reaction tank has to be taken into consideration along with the $\mathrm{pH}$ of the waste in the tank. 
When a desired $\mathrm{pH}$ is achieved valve 3 is opened to fill the clarifloculator $(\mathrm{CF})$ tank. Here we concentrate on removal of the sludge from waste. We perform this by opening valve 5after a specific period of time. After this process we pass this solution to the intermediate tank where the $\mathrm{pH}$ is again measured.

If the expected $\mathrm{pH}$ is not attained we open valve 6 which precede the waste to reaction tank for retreatment and the process continues. On the other hand if the $\mathrm{pH}$ is appropriate then its forwarded for further processing by opening valve v7 and v8.

\section{Future Scope:}

1. A GSM module can be added. So that we can directly message to manager on mobile.

2. Wireless communication within PC and module can be implemented.

3. An android application can be developed for making it more user friendly and mobile.

\section{Conclusion}

The project provides a cost efficient and user friendly alternative to the currently used system. This will not only help industry to improve its quality but also give a chance to utilize the resources economically and in the right direction. Moreover it provides them with an opportunity to strictly follow the environmental rules which on other hand is in favour of citizens also.

\section{Reference}

[1]. Alvaro E. Gil and Kevin M. Passino,Dept. Of Electrical and Computer Engineering, the Ohio State University."Feedback Control for Drinking Water Purification", unpublished

[2]. "Water Anti-Theft and Quality Monitoring System by using PLC and SCADA."International Journal of Electrical and Electronics Engineering Research (IJEEER) ISSN 2250-155X Vol. 3, Issue 2, Jun 2013, 355-364

[3]. Cláudia Telles Benatti and Célia Regina Granhen Tavares "Fenton's Process for the Treatment of Mixed Waste Chemicals"Faculdade Ingá - UNINGÁ, Universidade Estadual de Maringá - UEM, Brazil unpublished.

[4]. Li-An Lu, Ying-Shih Ma, Mathava Kumar and Jih-Gaw Lin Institute of Environmental Engineering National Chiao Tung University Hsinchu 300, Taiwan Department of Environmental Engineering and Health Yuanpei UniversityHsinchu 300, Taiwan "Influence of $\mathrm{pH}$ and $\mathrm{H} 2 \mathrm{O} 2$ dosage on the Decomposition of Carbofuran during the Photo-Fenton Process" 